\title{
Cost Estimation Using New Rules of Measurements 3 IN BIM 360
}

\author{
Islam Mohammed Khalil ${ }^{1}$ \\ ${ }^{1}$ BIM 360 MANAGER, King Abdullah Financial District (KAFD) \\ ANDALUS7111492@GMAIL.COM
}

\begin{abstract}
Cost estimates are prepared to different ends throughout the project lifecycle. Up front, the goal is to provide input for investment decisions. The cost estimate is used to determine the size of the required investment to create or modify assets and the elements of the building during the maintenance phase [1]. The Paper examines The implementation of BIM 360 as a common data platform for construction workflows in cost estimation by connecting all the stakeholders and provide the ability to collaborate all stakeholders in a single platform which is containing information model proceeds throughout the life cycle of the construction work and ideally it contains all the information, issues, associated with elements in the model composition ,measuring and dividing the building into elements associated with its information were required to address the problems associated with the measurement of building construction works and future maintenance works using New Rules Of measurements 3, at maintenance stage depending on elemental method of a building project and estimate the costs accurately.
\end{abstract}

\section{Keywords}

Cost Estimation, BIM 360, New Rules of Measurements (NRM3), Maintenance

\section{JEL Classification}

L74, C63, E17

DOI: https://doi.org/10.14311/bit.2019.02.02

Editorial information: journal Business \& IT, ISSN 2570-7434, CreativeCommons license (c) (i) published by CTU in Prague, 2019, http://bit.fsv.cvut.cz/ 


\section{Introduction}

Building maintenance is considered as a major activity in the construction industry because it is essential whether the buildings are large or small, simple or complex, located in urban or suburb. They must be well maintained to ensure their functionality and services during their life cycle. Traditionally, maintenance is defined as work on existing buildings undertaken to keep, restore or improve every part of a building, its services and surround to its original level and not to fall below the minimum acceptable level (British Standard 3811, 1993) [2]. Over the past, stakeholders of building asset have required the outcomes of building maintenance to meet certain criteria including re-instating physical condition to a specified standard; preventing further deterioration or failure; restoring correct operation within specified parameters; replacing components at the end of their useful/economic life with modern engineering equivalents; making temporary repairs for immediate health, safety and security reasons; and mitigation of the consequences of a natural disaster and assessing buildings for maintenance requirements (Queensland Government 2, 2017),[3]. Maintainability is an inherent characteristic of system design and installation with major maintenance implications as follows (Dell'Isola and Krik, 2003) [4].

- Selection of light fixtures, floor covering materials and interior elements.

- Plan for and implement a maintenance program.

- Perform most or all maintenance with full-time staff, or to contract for the services.

The quality of maintenance activities is significantly influenced by the amount of budget allocated. A common challenge is recognized in allocating maintenance budget with the argument during the process of formulating the maintenance funding (Lee and Scott, 2008) [5]. It is evidence that the cost of all maintenance works annually will exceed yearly budget and then the decision makers have to decide which tasks should take priority this year to maintain the building within the funds available and what could be delayed to the following year (NWS Heritage Office, 2004) [6]. Therefore, a proper maintenance cost plan would enable building owners to get optimal of maintenance outcome.

Building Information Modeling (BIM) is an emerging technology throughout the world in the Architecture, Engineering, and Construction (AEC) industries. BIM technology provides users with accurate and consistent building/project data and information, accommodating the functions needed to model the building and provides a virtual view of it. Building information models are increasingly used, for several purposes by the diverse stakeholders during the different phases of the project and building lifecycle. BIM revolutionize the AEC industry, being not only a change between CAD and parametric modeling with 3D capabilities, but a change of workflows, methodologies, process, and relations. Basically, it changes the way business is done throughout the industry. Although all of these changes may seem too much to be easily accepted by the industry, the benefits are much greater, making BIM the future for the industry [7]. Emerging Building Information Modelling (BIM) is one of the leading technologies being used in different construction applications such as energy simulation, sustainability, facilities management, risk management and cost estimation [8]. Estimate costs are the process of developing an approximate monetary resource (budget) needed in order to complete the project activities. It is necessary to determine the amount of cost that is required to complete the work. Aside from determining the cost, it is also necessary to allow the project manager to weigh the benefits against the cost to find out if the project is sensible or not. It also allows the project manager to determine if there are other necessary funds to support the project. Lastly, it serves as a guideline to ensure that you have enough funds to complete the project.

New Rules Of Measurements 3 which provides a structured basis for measuring cyclical repairs and replacements and annualised maintenance of building components and calculate the cost of dilapidated elements of buildings [9]. This volume provides a structured basis for measurement of building maintenance works, encompassing the annualized maintenance and life cycle major repairs and replacements of constructed assets and building components - which are carried out post construction procurement and throughout the in use phases of the constructed assets, or built environment. The prime function of these rules is to provide consistent rules for the quantification and measurement of building maintenance work items - for the purposes of producing order of cost 
estimates, elemental cost plans and detailed asset specific work, throughout the entire building life cycle, The process of economic evaluation of the whole life cycle costing (WLCC) of all construction, operation and maintenance related costs during ownership is what is commonly referred to as life cycle costing. It provides a method foOr quantity surveyors/cost managers to assist building owners and project teams in selecting the optimum solution for their circumstances and helps inform the decisionmaking process at various stages during the feasibility, design development and procurement and the in-use phases of a building or facility using BIM 360as a large single platform which has the ability to collaborate all stakeholders ، which improve decision-making throughout the constrcuction project life cycle BIM 360 Build which combines mobile technologies at the point of construction and maintenance with cloud-based collaboration and reporting which improves the quality and profitability for construction and capital project [9]for making a dilapidation servey for all issues in the financial, district of KingAbdullah in a single repository using the mobile technology integrated with BIM 360 BUILD depending on.

\section{Literature review}

\section{Maintenance Work Types}

Maintenance can be categorized according to answer questions why and when it happens. Figure 1 below present a summary of categorization of maintenance work classification which enables organizations to provide consistent services to customers' satisfaction. There are two common terms of maintenance types: planned/preventive maintenance and corrective/unplanned maintenance with other categories as shown in Figure 1. Commonly, planned/preventive maintenance aims to prevent major breakdowns to ensure a building continues at peak efficiency through regular inspection and repair (Madureira et al., 2017) [10]. Preventive maintenance is planned, based on cyclic maintenance actions such as cleaning, local repair and local replacement/treatment to prevent deterioration in advance (Ruparathna, Hewage and Sadiq, 2018; Queensland Government 2, 2017; EU Standard, 2009) [11]. Statutory maintenance, time-based, condition-based, predictive, reliability-centred maintenances are sub-categories of planned/preventive maintenance (Queensland Government 2, 2017; Ruparathna et al., 2018; Wang et al., 2014) [12].

Although well-planned, maintenance work must always be ready to respond to unexpected breakdown. Corrective/unplanned maintenance consists of repair and replacement elements due to the failure of preventive maintenance or natural wear and tear that sometimes is called reactive maintenance (Ruparathna et al., 2018; Queensland Government 2, 2017; EU Standard, 2009; Muyingo, 2009) [13]. There will be preventive and corrective maintenance work in any maintenance strategies. The planner should ensure that there is no conflict or duplication between reactive actions and planned operation. The proposed planning of maintenance activity should base on the estimated service life of building properties, cost rationalization and users' satisfaction.

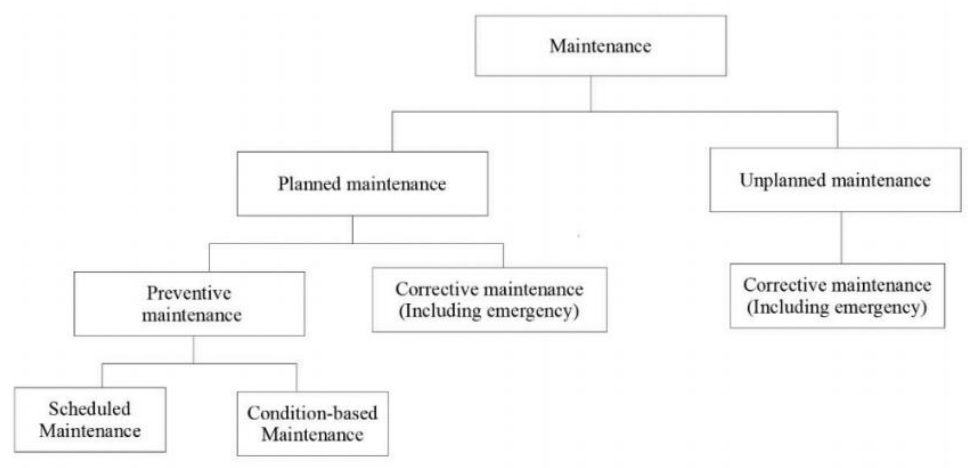

Figure 1: Types of maintenance (Chanter and Swallow, 2007) 
The preventive maintenance is justifiable for health, safety and environmentally significant components/items for both items whose condition can or cannot be monitored. The corrective maintenance is appropriate for non-significant components/items and other items which the cost of applying time-based preventive maintenance is less than the cost of applying corrective maintenance (Horner, ElHaram and Munns, 1997) [14]. Based on the advantages and disadvantages of the above maintenance types, Table 1 categorises the maintenance hierarchy for building components/systems. Source: Ruparathna et al., (2018).

Table 1: Maintenance hierarchy for building components

\begin{tabular}{ll}
\hline Type of maintenance & Type of equipment \\
\hline Corrective maintenance & Small parts and equipment. \\
& Noncritical equipment/item. \\
& Equipment unlikely to fail. \\
& Utility significant items whose condition cannot be \\
& monitored \\
\hline Preventive maintenance & Equipment with known failure pattern. \\
& Recommended by the manufacturer. \\
& Consumable equipment. \\
& Equipment with subjected to wear
\end{tabular}

The overall maintenance plan must provide information to allocate and prioritize sufficient resource and funds for the maintenance operations. The annual list of required maintenance with an estimated cost in the five-year programme usually follows. Alternatively, the repairs will be carried out in order of priority. Therefore, some maintenance will be deferred since the resource is limited. It should be noted that the buildings will require a certain of level of maintenance whatever the current economic situation.

\section{Maintenance Cost Planning and Estimating}

Maintenance cost includes all costs of keeping the building up to an acceptable standard. It relates to the direct cost of maintenance such as spares, labours, equipment and tools as well as indirect costs such as administration, management and the inevitable overhead costs (El-Haram and Horner, 2002)[15]. When the demands of maintenance are identified, cost of the maintenance should be a prior estimate to measure resource availability and how much work should be scheduled in each period. Although cost estimates for building maintenance are normally prepared over the period to predict the likely cost of such works over the life of the buildings, they can be considered in a single annual maintenance programme. The main purposes of a cost plan for building maintenance are defined as listed below (RICS, 2015). - Determine the target cost limit for maintaining programme works. - Inform setting the annualised maintenance budgets and available funding constraint. · Provide cost information to assist decision makers to make informed decisions. - Inform what asset investment are funded or not funded and then revise life cycle cost plan. - Ensure the employer is provided with best value for money from maintenance spent. Like any program or plan, maintenance budgets will be subjected to change and adjustment and it must be based on forecasting or predicting aiming to best utilise fixed maintenance resource to meet the fluctuating maintenance workload (Al-Fares and Duffuaa, 2009) [16]. Total maintenance cost is the sum of the cost of preventive maintenance and corrective maintenance as shown in Figure 2. Having a proper preventive maintenance strategy can reduce corrective maintenance cost, leading to reach optimal maintenance zone. The optimal zone is where the two costs are balanced. Once funds are approved for the maintenance budget, efficient use of this money requires wise internal allocation of the funding at the operational level or locating this optimal zone. 


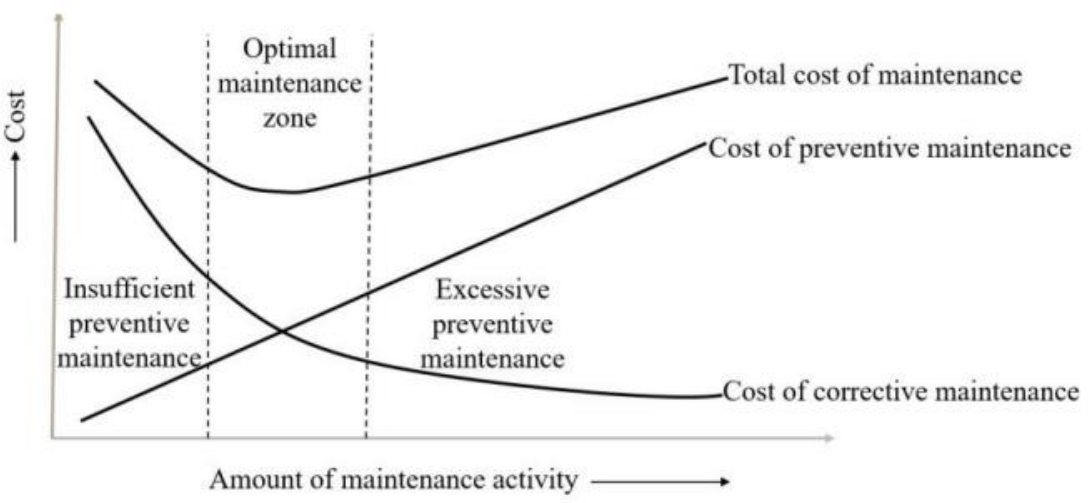

Figure 2: Total of maintenance cost (Douglas, 2017)

Douglas (2017) also summarised five stages in the optimisation process, that should be embedded in the design phase but will offer benefits to any state of a building lifecycle: (1) identify critical functions/elements/areas; (2) understand the failure models and effects; (3) evaluate existing maintenance; (4) apply predict maintenance technique; and (5) recommend changes to maintenance strategy according to findings of best practice. Cost planning and estimating of maintenance work require detailed information such as maintenance requirements or the employer's brief for maintenance work throughout the life of the building over the short, medium and long-term. Some agreements remain as maintenance works can be challenging to cost accurately due to lack of reliable information required as listed below:

- Type of buildings/asset/facility and the functional usage.

- Occupancy details: tenure detail, hours of operations, usage of space.

- A statement of building/asset/facility (age of the building, last major refurbishment, etc.). Location and building description.

- Aims of the maintenance programme, maintenance strategy. A limited number of the building components such as roofs, paintwork, woodwork and building services play a large part in maintenance cost (Straub, 2003), [17]. Therefore, identifying significant factors affecting the maintenance cost and the relationship between the factors such as building characteristics, tenant factors, maintenance factors, political factors might help to control the factors to optimise the maintenance cost. While planned maintenance works have different technical specifications resulting in differences in requirements for maintenance resource, leading to different approaches to calculating the costs for specific scheduled maintenance work (Mirghani, 2009) [18], the unplanned maintenance costs usually are budget based on historical data showing by percentage of actual breakdown cost and total cost of maintenance.

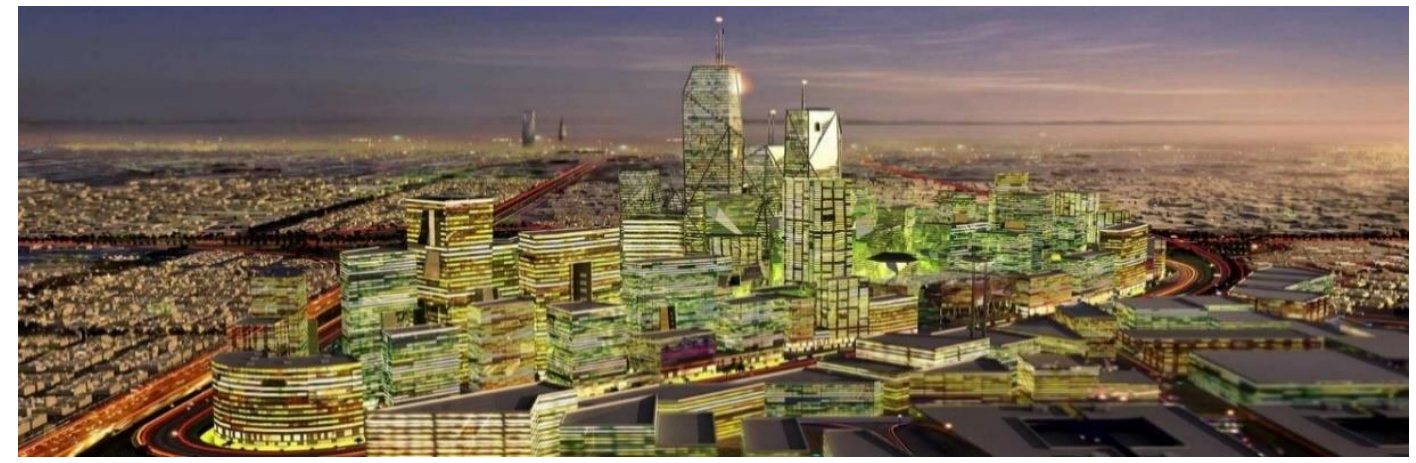

Figure 3: Saudi Arabia's King Abdullah Financial District 


\section{Research Methodology}

Bryman and Cramer (2011) propose that a mixed method approach can provide a more insightful, yet informative investigation for the phenomenon being investigated. Within a mixed method, approach data can be collected within a short period of time. Furthermore, Saunders et al (2007) points out that qualitative approaches are best suited to analyze content that is non-numerical in nature. For this study, data was attained by new strategy which realize one of important characteristics of BIM which is common data environment (CDE) through BIM 360 depending on new rules of measurements (NRM 3)

In the project KINGABDULLAH FINANCIAL DISTRICT (KAFD), which is a smart city development worth \$11.6bn,construction near King Fahad Road in the Al Aqeel area of Riyadh, being undertaken by the Riyadh Investment Corporation on behalf of the Pension Authority of the Kingdom of Saudi Arabia, consisting of 59 towers in an area of 1.6 million square meters. It will provide more than 3 million square meters of space for various uses, 62,000 parking spaces and accommodation for 12,000 residents, [19], the client required cost estimation for the maintenance work accurately and rapidly, Therefore, the new strategy moved towards a platform collaborate between all stakeholders and collect all the data in one repository which was BIM 360 depending on a reference which provide the structure method of the Templates which will contain all the data for cost estimation of collecting data which was new rules of measurements 3 (NRM 3 ) from RICS.

(1) - Using the elemental structure of new rules of measurements 3 (NRM 3)

(2) - Using BIM 360 as a common data environment ( CDE)

- $\quad$ Stage 1 - Using the elemental structure of new rules of measurements 3 (NRM 3 )

New Rules of Measurements 3 - RICS (NRM 3) provides essential guidance on the quantification and description of maintenance works for the purpose of preparing initial order of cost estimates during the preparation stages of a building project, elemental cost plans during the design development stages (pre-construction) and detailed asset-specific cost plan (post-construction) and throughout the in use phases of a building project or facility.

In this step, the elemental method are dividing the building to

- Level 1 - elements

- Level 2 - sub elements

- Level 3-components

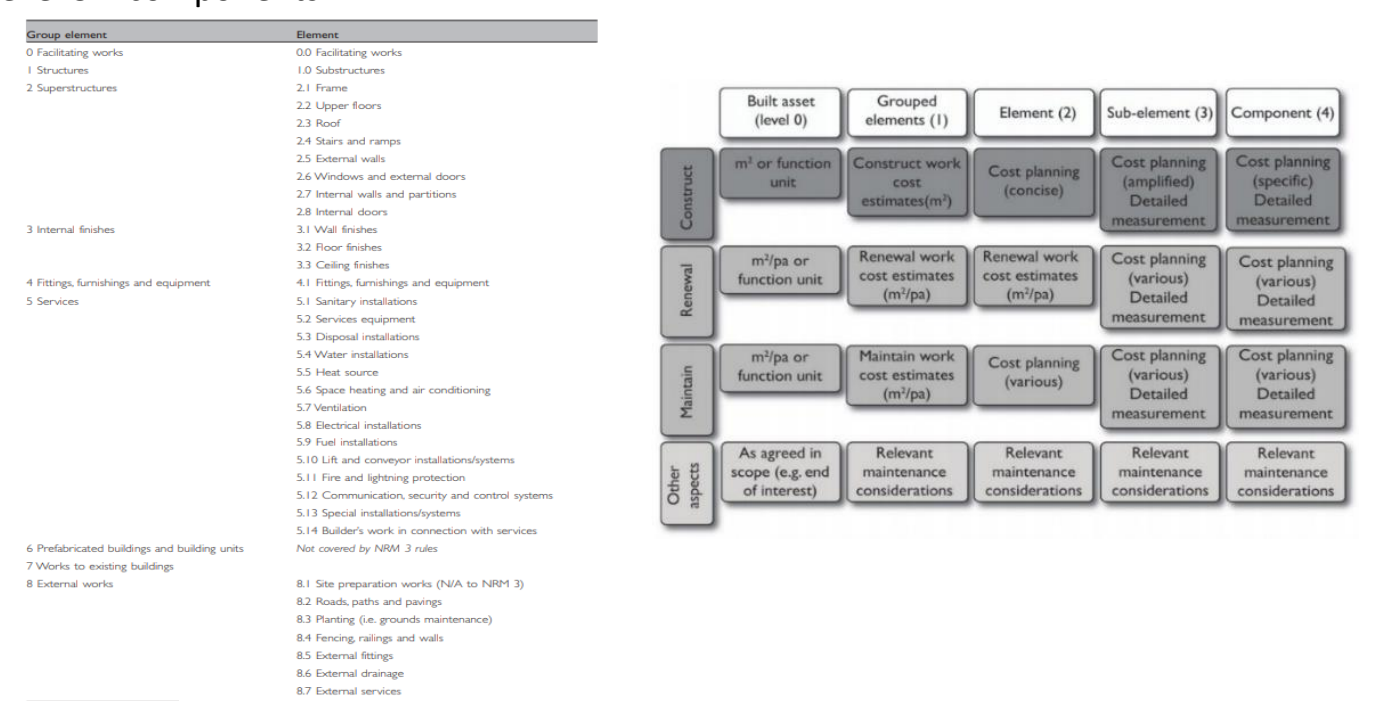

Figure 4: Elemental Method of Cost Estimation 


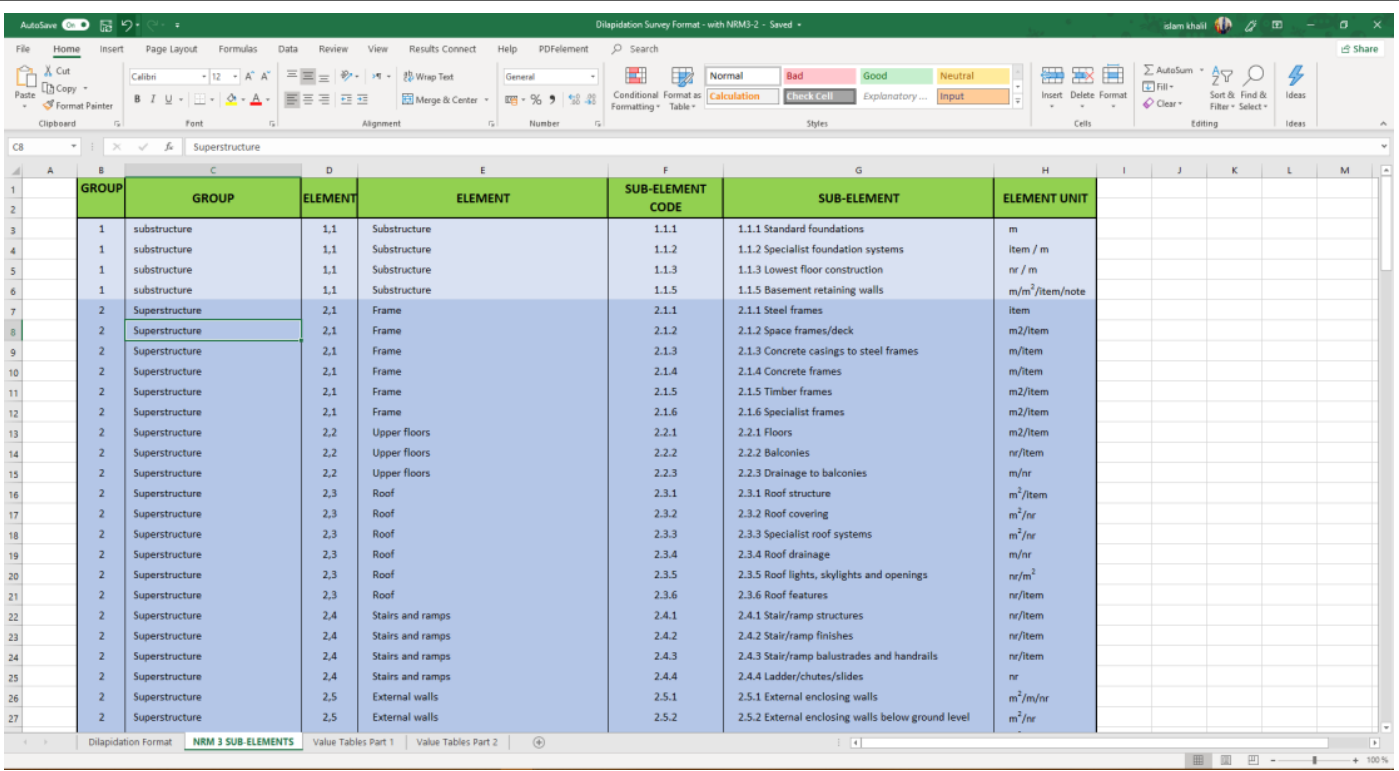

Figure 5: Elements \& Sub-Elements with Units

In this step, the building is divided to elements and sub element with its units as shown in Figure (5) for calculating the total estimated cost of both capital building and maintenance works, If suitable information is available, then elemental unit quantities (EUQ) are measured for an element in accordance with the rules and priced with suitable elemental unit rates (EUR) to ascertain the cost target for an element. Where insufficient information is available for a particular element, the EUQ for the element is based on the GIFA. The equation for calculating the cost target for an element is therefore [20],

Where:

$$
\begin{aligned}
& c=a \times b \\
& a=\text { elemental unit quantities } \\
& b=\text { elemental unit rates (EUR) }
\end{aligned}
$$$$
c=\text { cost target (for element) }
$$

\section{- $\quad$ Stage 2 - Using BIM 360 as a common data environment (CDE)}

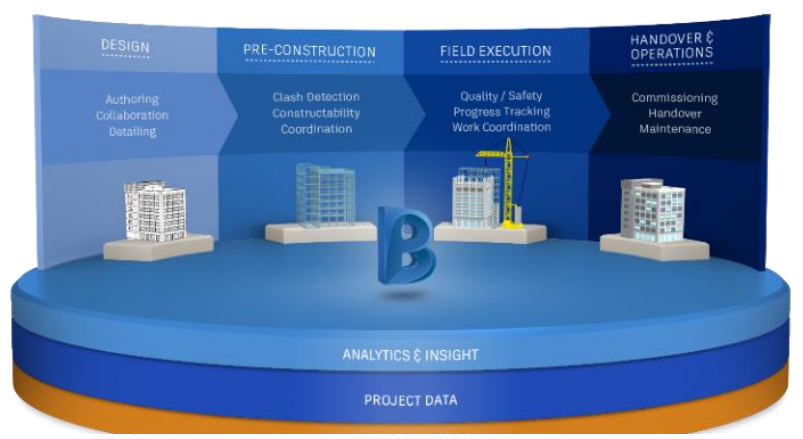

Figure 6: BIM 360 platform 
BIM 360 is a unified platform connecting your project teams and data in real-time, from design through construction, supporting informed decision-making and leading to more predictable and profitable outcomes. [21],

BIM 360 BUILD is a construction management software which achieve:-

- Improve construction quality control and safety programs

- Create, assign, and manage issues, RFls, and submittals

- Track Field Performaance with dashboards and reports

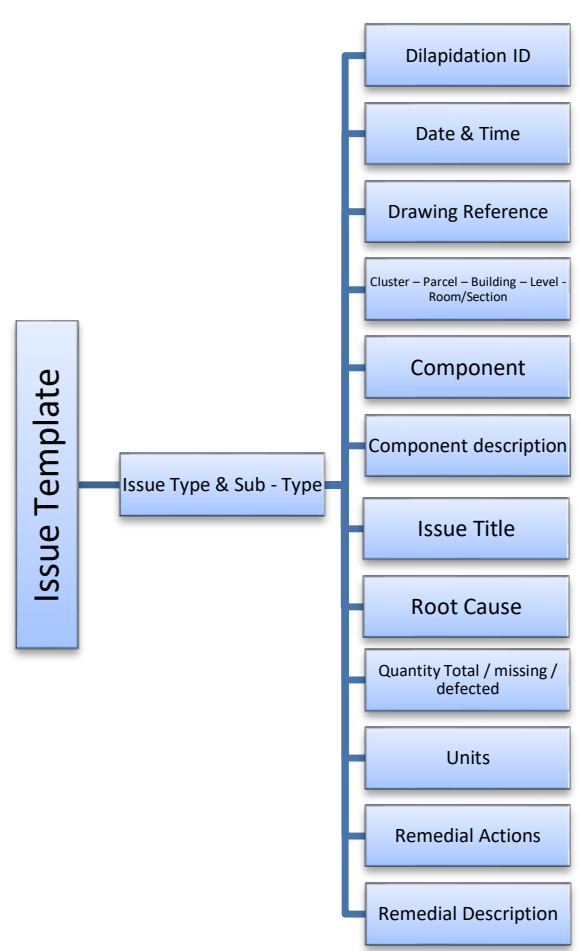

Figure 7: Hierarchy of Issue Template in BIM 360 Build

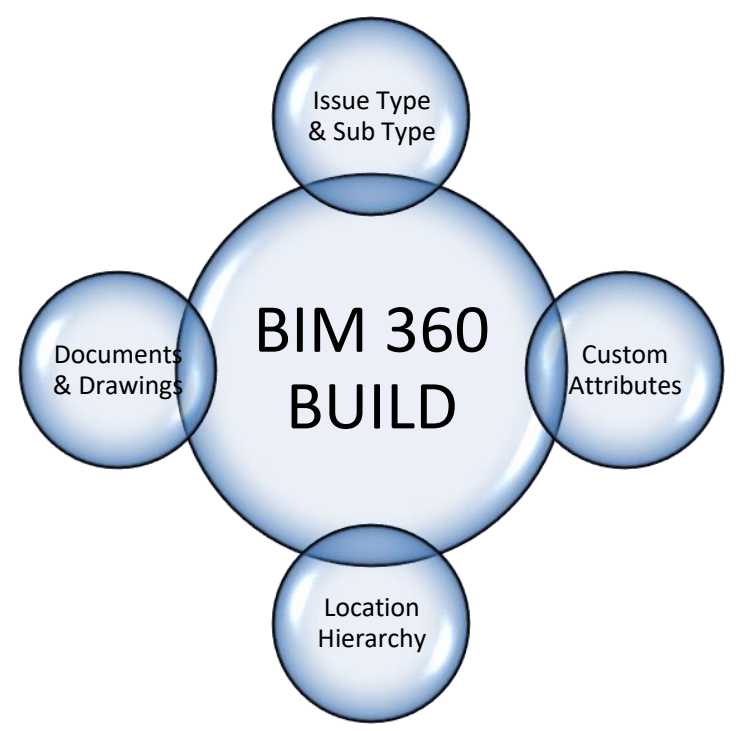

Figure 8: Stages of Issue Template in BIM 360 Build

And the Issue Template in BIM 360 is divided to 3 levels:

* Level 1 - Issue Type

* Level 2-Issue Sub - Type

- Level 3 - Custom Attributes

as shown in Figure 5. 


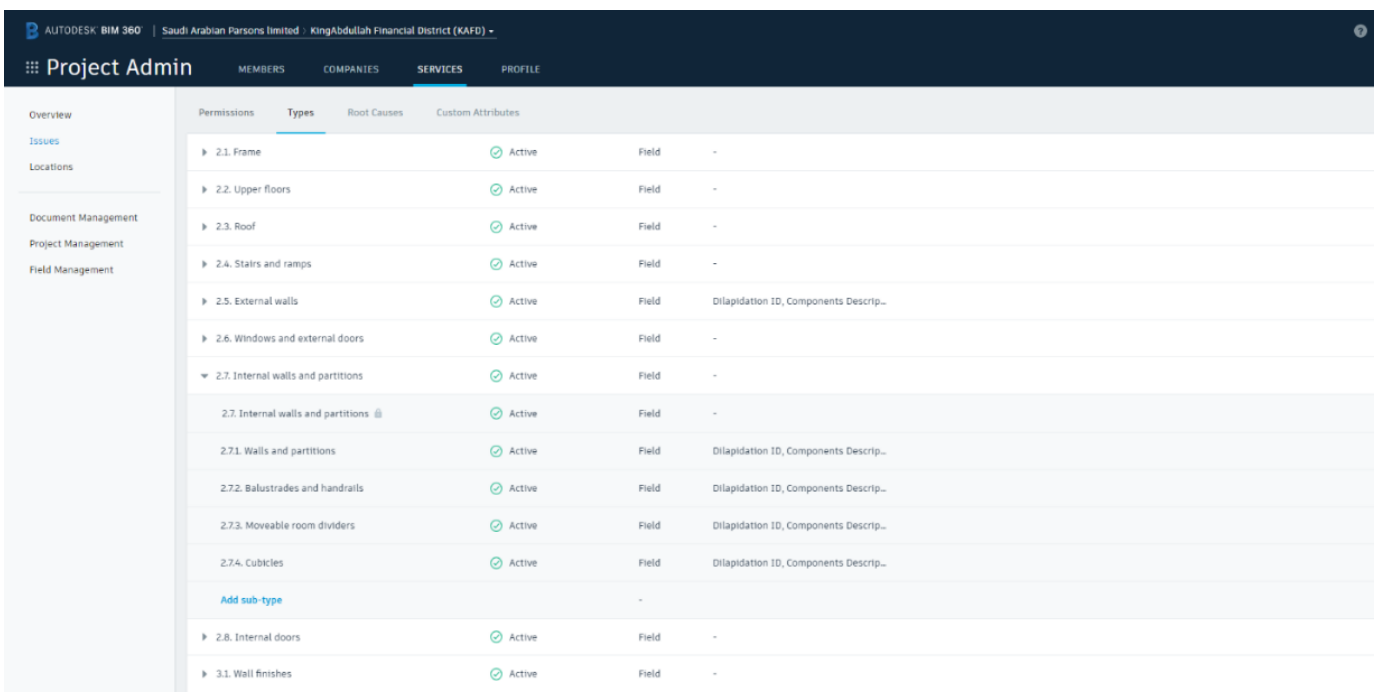

Figure 9: Issue Types \& Sub-types in BIM 360 BUILD
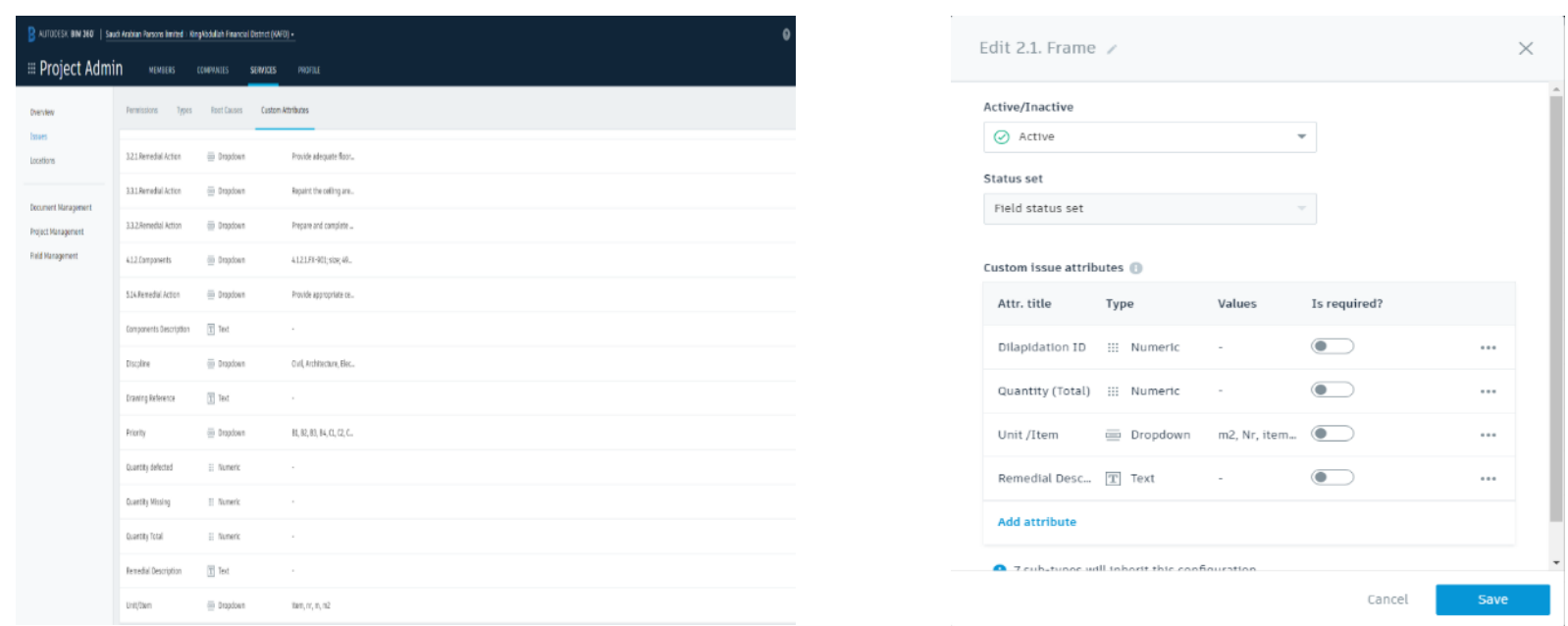

Figure 10: Issue Custom Attributes in BIM 360 BUILD

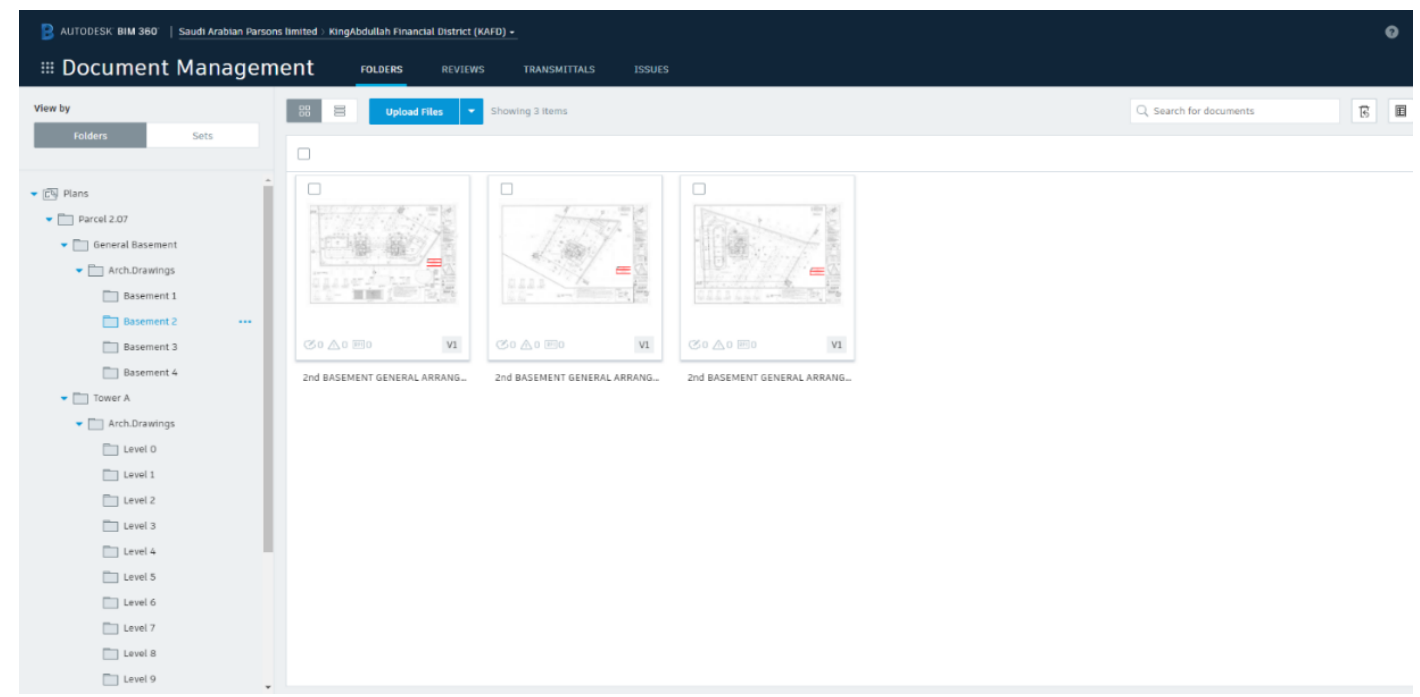

Figure 11: The Drawings in BIM 360 Docs 


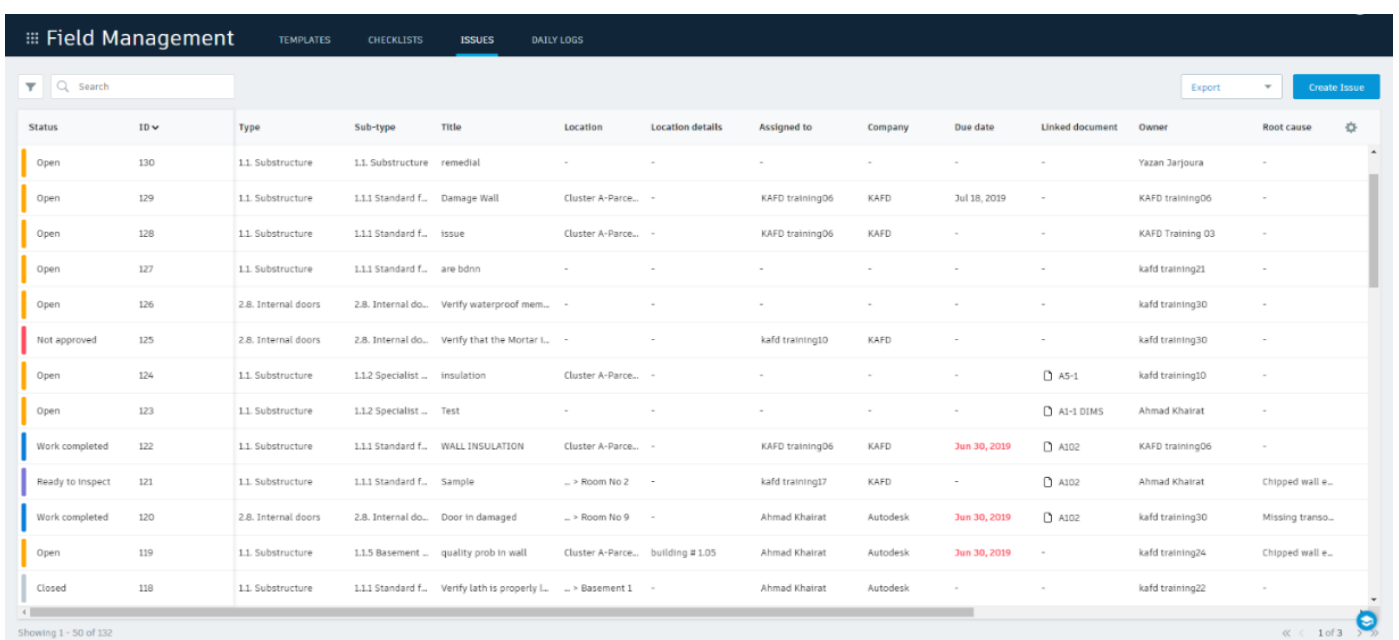

Figure 12: The List of Issues in BIM 360 Build

Finally The Report of all issues in the project was extracted as shown in Figure 13.

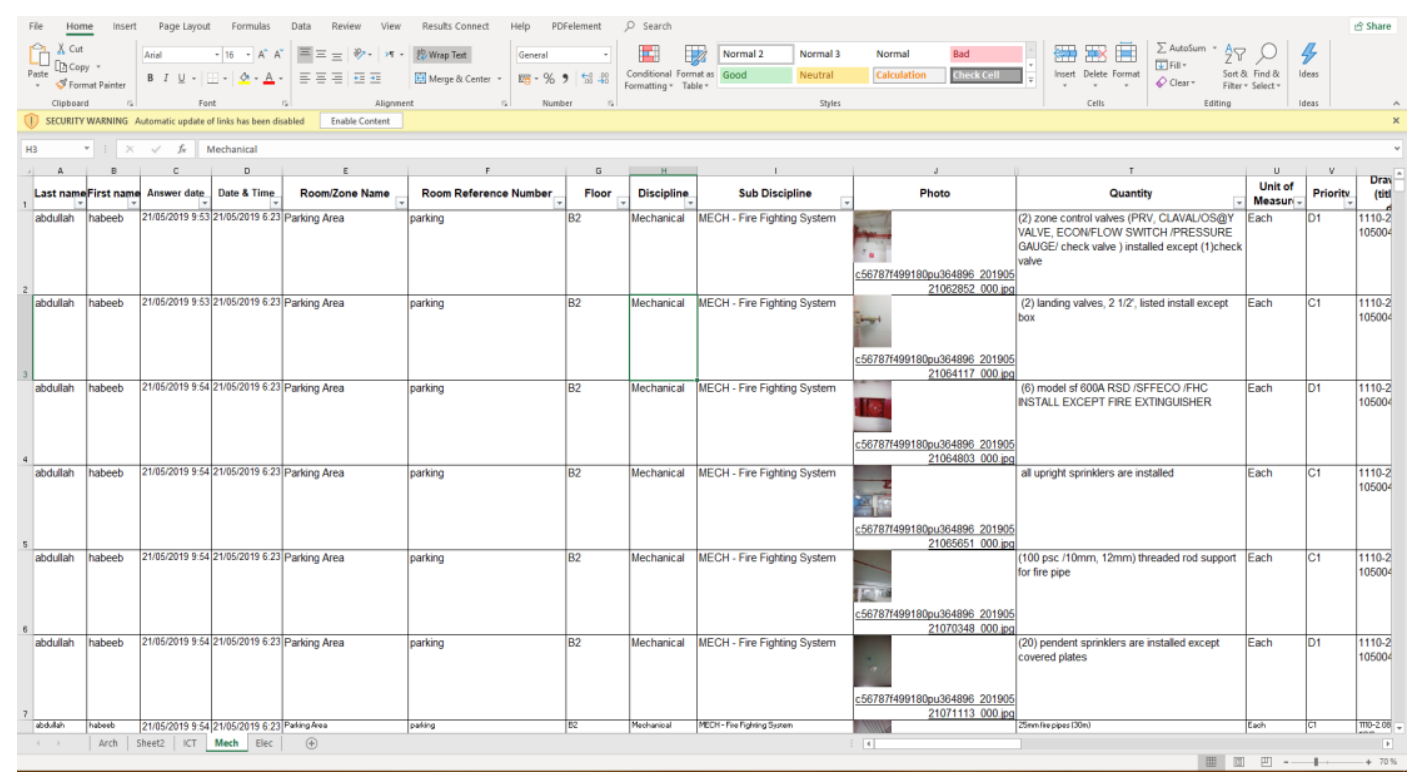

Figure 13: The Final Report Extracted from BIM 360

\section{Conclusions}

The literature review reveals that maintenance decisions made have a significant implication on maintenance cost, and estimating the cost is needing accurate data , so, the best way for collecting all data in one repository and collaborate between al the stakeholders on the site by BIM 360 BUILD for assuring that all data are corrected and not repeated for extracting them in the report that is presented to the client depending on NRM 3 , after that, following up and resolving all these issues by using BIM 360 BUILD. 


\section{References}

[1] https://www.costengineering.eu/

[2] British Standard 3811 (1993) Definition of Maintenance.

[3] Batalović, M, Sokolija, K, Hadžialić, M and Batalović, N (2017) Maintenance and operation costs model for university buildings. Tehnički Vjesnik, 23(2), 589-598.

[4] Dell'Isola, A and Krik, S J (2003) Life Cycle Costing for Facilities. Kingston, MA: Reed Construction Data.

[5] https://www.rics.org/globalassets/rics-website/media/upholding-professional-standards/sectorstandards/construction/nrm_3_building_maintenance_works_1st_edition_pgguidance_2013.pdf

[6] Erdogan, B (2008) Organizational Change Management for the Implementation of Collaboration Environments. PhD Thesis, Loughborough University.

[7] Bhuskade, S.2015," Building Information Modeling (BIM)",India. Volume: 02 Issue: $02 . p p ~ 843-841$.

[8] F.H. Abanda, L. Byers, An investigation of the impact of building orientation on energy consumption in a domestic building using emerging BIM (Building Information Modelling), J. Energy 97 (2016) 517-527

[9] New Rules Of Measurements 3 - RICS

[10] https://www.autodesk.com/bim-360/

[11] EU Standard (2009) EN - 13306 - Maintenance Terminology.

[12] El-Haram, M A and Horner, M W (2002) Factors affecting housing maintenance cost. Journal of Quality in Maintenance Engineering, 8(2), 115-123.

[13] Al-Fares, H K and Duffuaa, S O (2009) Maintenance forecasting and capacity planning. In: Ben-Daya, M, Duffuaa, SO, Raouf, A, Knezevic, J, Ait-Kadi, D (Eds.) Handbook of Maintenance Management and Engineering. London: Springer

[14] Douglas, C (2017) EMIT optimisation: Getting more out of existing equipment for less. RISK World(31),/4-5.Availablefrom http://www.risktec.tuv.com/media/374310/riskworld\%20newsletter\%20-\%20medresolution\%20\%20single\%20pages.pdf [Accessed 17/06/2018].

[15] Haroun, A E (2015) Maintenance cost estimation: Application of activity-based costing as a fair estimate method. Journal of Quality in Maintenance Engineering, 21(3), 258-270

[16] Al-Fares, H K and Duffuaa, S O (2009) Maintenance forecasting and capacity planning. In: Ben-Daya, M, Duffuaa, SO, Raouf, A, Knezevic, J, Ait-Kadi, D (Eds.) Handbook of Maintenance Management and Engineering. London: Springer

[17] Dell'Isola, A and Krik, S J (2003) Life Cycle Costing for Facilities. Kingston, MA: Reed Construction Data.

[18] EU Standard (2009) EN - 13306 - Maintenance Terminology.

[19] https://www.google.com/KAFD/

[20] New Rules Of Measurements 3 - RICS

[21] https://www.autodesk.com/bim-360/ 